\title{
Show Me Yours: Developing A Faculty- Wide Interdisciplinary Initiative In Built Environment Higher Education
}

Stephanie Wilson, University of New South Wales, Australia Lisa Zamberlan, University of New South Wales, Australia

\begin{abstract}
In the competitive market of higher education, government funding agencies consider universities accountable for ensuring a better alignment between educational processes, graduate capabilities and real world employability. Workforce leaders have developed new expectations about the capabilities of graduating students, expecting to employ graduates who have more sophisticated understandings of the complexity involved in undertaking projects and working in the field. Graduates are expected to demonstrate well developed inter-professional literacy, be able to successfully navigate across professions in workplaces, and to effectively contribute to large projects involving a diverse range of roles and responsibilities. There is growing awareness within the sector that universities should work in partnership with students to tackle local and global challenges and that often these challenges cannot be addressed adequately by a single discipline. Stone, Bollard and Harbor (2009) note that as society has become more complex, research questions have changed, and the "structures of earlier times no longer accommodate the research needed and the teaching that emanates from this research" (p.322). Increasingly, scholars are looking across traditional disciplinary boundaries in new ways to address socio-cultural concerns. The extent of scholarship into the rise and prominence of interdisciplinary collaboration in higher education, along with the external drivers that support this paradigm in education and practice, shifts discussion within faculties from the "benefits of interdisciplinary approaches to pragmatic questions of how to develop and sustain interdisciplinary programs" (Stone et at. 2009, p.323). This paper describes a framework for the introduction of common learning experiences (CLEs) in the Built Environment Faculty (BE) at the University of New South Wales to more adequately prepare students for future professional settings. The paper discusses the initiative in the context of recent research on interdisciplinary learning and teaching in the built environment and higher education more broadly, and discusses the conditions that are likely to support and sustain the initiative into the future.
\end{abstract}

Keywords: Built Environment; Interdisciplinarity; Common Learning Experience; Collaboration

\section{FACULTY OF BUILT ENVIRONMENT AT UNSW}

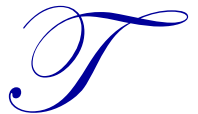

his paper describes a faculty-wide initiative to embed interdisciplinary experiences into the undergraduate curriculum in the Faculty of Built Environment (BE) at the University of New South Wales (UNSW). It draws on some of the key literature on interdisciplinary education in the built environment and higher education and describes how key themes and questions arising from the literature were used to inform the development of the initiative. The approach described involves ensuring that all undergraduate students are given opportunities to progressively develop interdisciplinary knowledge and skills during their degree, and building staff capacity for collaborative teaching and research.

There is a wide spectrum of possibilities for building in interdisciplinary activities across the Faculty. What we want to overcome is a silo mentality that impedes students' opportunities to interact with each other across programs. It is our societal obligation to make this interdisciplinarity happen in a genuine way. (BE Faculty Retreat, 2010) 
The Faculty of Built Environment at the University of New South Wales is a collective of disciplines involved in design enquiry and built environment practice. These disciplines include architecture, interior architecture, landscape architecture, industrial design, planning and urban development, urban design, sustainable development and building construction project management. There are currently 14 degree programs at the undergraduate and postgraduate level involving 71 full time academics, approximately 402 contract staff and 2900 students.

In 2009 and 2010 new executive and management teams were recruited to the faculty to facilitate change in its positioning, education and research practices. Following a strategic planning process (BE Strategic Plan 2009) developed in line with wider institutional strategic directions (UNSW B2B - Blueprint to Beyond), initiatives under five operational clusters were articulated: organizational structure, curriculum development, research, staff development, and finance. Initiatives for the curriculum development cluster of the strategic plan were developed with academic staff, external facilitation, and the Built Environment Executive (BEE).

The Program Directions 2011-2015 document which followed articulates a number of pedagogical targets for the BE Faculty. One of these targets is to integrate interdisciplinary pedagogical experiences into the curriculum that reflect contemporary, collaborative work practices in industry. This strategic direction reflects a faculty-wide investment in renewed curricula across all undergraduate, postgraduate and graduate degree programs, capitalizing on existing strengths and refocusing teaching and research resources. The articulation of the student experience from undergraduate to higher degree research training established in this document highlights the necessity of an interdisciplinary education and the critical role of research-led enquiry to this educational experience.

The impetus for strategic curriculum development in higher education has significant external drivers for change in the Australian context. The federal government has demonstrated a strong commitment to graduate employability, holding Universities accountable for quality assurance in the development of graduate capabilities and market preparedness (Billett, 2009). Employers expect graduates to demonstrate inter-professional capacities in the workplace, be able to synthesise skills across increasingly complex projects and contribute effectively in new and diverse work practices. In response, leading Australian universities are actively investing in new, enterprisewide approaches to addressing this issue in an effort maintain distinction amongst competitors, realign with shifting market and professional trends and compete in a sector increasingly responsible for quality assurance in educational delivery.

The common learning experiences (CLE's) discussed in this paper represent one project in a series of interdisciplinary initiatives that signify a redirection for the Faculty. The CLE initiative aims to introduce genuine interdisciplinary experiences across the undergraduate curriculum to better prepare students for the realities of the rapidly changing professional environment. Many courses within BE's individual programs are already effectively addressing interdisciplinary learning, issues of globalization and social engagement, and meeting authentic industry needs. However, these courses exist due to the forward thinking of individual academics and will only remain if these individual commitments continue. The challenge of the CLE initiative is to develop meaningful and sustainable faculty-wide collaboration between staff and students and create a distinguishing marker of change in faculty learning, teaching and research practices. Across 2011 and 2012 working groups of academic staff, facilitated by staff from the Office of the Associate Dean Education, developed a business case for the initiative for approval across faculty committees and sponsorship by the executive team (BEE). The resulting framework, described below, locates interdisciplinary practice at two points across each of the seven undergraduate degree programs.

A starting point for this initiative was to investigate current thinking about the role of interdisciplinary learning and teaching in higher education, and more specifically, to understand recent thinking, strategies and challenges related to interdisciplinary education in the built environment field.

\section{INTERDISCIPLINARITY IN THE BUILT ENVIRONMENT}

There is growing awareness within the sector that universities should work in partnership with students to tackle local and global challenges and that often these challenges cannot be addressed adequately by a single 
discipline. Stone et al. (2009) note that as society has become more complex, research questions have changed, and the "structures of earlier times no longer accommodate the research needed and the teaching that emanates from this research" (p.322). Increasingly, scholars are looking across traditional disciplinary boundaries in new ways to address socio-cultural concerns. This is supported by the Boyer Report (1998) that recommends that research universities remove barriers to, and create mechanisms for, interdisciplinary undergraduate education.

Research into the rise and prominence of interdisciplinary collaboration prompted Stone et al. (2009) to suggest that discussion within faculties has tended to shift from the "benefits of interdisciplinary approaches to pragmatic questions of how to develop and sustain interdisciplinary programs" (p.323). The authors note that while interest in interdisciplinary programs has increased in recent years, the understanding of what constitutes interdisciplinary programs varies considerably. This has led to a tendency for people to talk at cross-purposes, and initiatives frequently suffer as a result. The authors argue that diversity is one of the concept's strengths and suggest this diversity should be embraced and explored.

Gann and Salter (1999) highlight a gap between discipline-based education and practice in the built environment, stating that the "challenges of practice do not present themselves in disciplines and that interdisciplinary skills are critical to problem solving in the conditions presented in the built environment where many variables, together with significant levels of uncertainty and risk are found" (cited in Chapman, 2009, p.11). Similarly, Edwards, Campkin and Arbaci (2009) suggest that "given the number of agencies and the complexity of institutional and professional relationships in the production, management and regulation of the built environment, many students entering built environment professions leave university without a sufficient understanding of these diverse actors, and the formal and informal interactions and social dynamics between them" (p.39). The CLE initiative aims to address these shortcomings.

Chapman (2009) draws attention to the wide variety of concerns and actions across the built environment disciplines, "from the realisation and management of development and places through to spatial planning at great territorial scales" (p.10). All involve the development and management of our environments. Quoting Cortese, Chapman states that places where "interactions between population, human activities, and the environment... for a secure, just, and environmentally sustainable future are among the most complex and interdependent issues with which society must deal" (p.16). He highlights the significant responsibilities attached to the built environment disciplines and the need to ensure genuine collaboration and additional benefits from the results of our combined actions. benefits:

The advantages of interdisciplinary education are well documented. Gammal identifies the following

- It is reflective of life, which is not segmented into discrete disciplines;

- It allows for the use of multiple approaches and applications of skills for problem solving;

- It can provide a broader context for new information;

- It allows for a broad use of diverse experiences and knowledge bases;

- It encourages creativity and creative thinking;

- It allows for greater flexibility;

- It can provide expanded opportunities for the application of theory;

- $\quad$ It provides a good introduction and foundation for various disciplines;

- It allows for the use of diverse perspectives;

- It can enhance the ability to synthesise and integrate information. (pp.7-8)

These benefits suggest that interdisciplinary opportunities can be introduced to provide a broader context, add value to, and complement students' study in their chosen discipline. Davies and Devlin (2007) address the concern that an education that is too broad might not provide sufficient expertise in the home discipline to "allow an adequate appreciation of when interdisciplinarity will be desirable" (p.4). They suggest however that as some interdisciplinarity is desirable, the "questions of how best to incorporate it into students' experiences are key" (p.4). 
In 2010, a project exploring professional education in Built Environment and Design in Australia was published by the Australian Learning and Teaching Council (Savage, Davis and Miller, 2010). The study began by scoping the challenges facing Built Environment and Design education. From this it became clear to the researchers that the main challenge for most parties (academics, graduates, professionals) centres on the "ways in which courses prepare graduates for the pace, diversity and flux of contemporary professional practice" (p.i). One of the three recommendations that emerged from the study was to "[d]evelop and implement better transition-to-work strategies" (Recommendation 3). Specifically, the study states that "developing ways of improving graduates' capacity to engage in good judgement, critical thinking and lifelong learning is necessary" (p.v). All stakeholders emphasised the importance of critical thought, problem solving and lifelong learning. The development of 'thinking' was the prime consideration for professionals.

Both Jones and Merritt (1999) and Gammal (2009) highlight clear links between critical thinking and interdisciplinary understanding. Gammal suggests that the focus of interdisciplinary courses is primarily "on the development of astute critical thinking abilities, the use of multiple perspectives in problem-solving, and the ability to draw connections between related issues - skills that transcend all disciplines and remain applicable in the pursuit of solutions to any problem" (p.7). The introduction of faculty-wide core interdisciplinary experiences is a key strategy for improving students' successful transition to contemporary professional practice. As suggested by Corkery (2007) "professional degree programs in built environment disciplines that do not prepare students to work closely with colleagues in other fields will not be meeting their responsibility to prepare graduates who are career ready" (p.1).

The literature cited above, and case studies of interdisciplinary learning and teaching in the built environment (see Wilson, 2011), provides strong support for the introduction of core interdisciplinary learning experiences in built environment higher education. However, only a small proportion of the literature attempts to distinguish different levels of interdisciplinarity and how these levels might translate into the student learning experience.

\section{LEVELS OF INTERDISCIPLINARITY}

Central to the discussion about the development of common learning experiences in the Faculty was the question: What sort of knowledge, skills and/or dispositions might we expect students to develop at the first year level and how might this change as they progress through their undergraduate degree?

While the literature provides clear descriptions of the distinctions between interdisciplinary learning and other experiences that step outside traditional disciplinary learning (e.g. multidisciplinarity and cross-disciplinarity), discussions about the variants of interdisciplinarity are less common. Davies and Devlin (2007) provide a useful way of looking at different levels of interdisciplinarity that range from "benign to radical" (p.3). These variants are useful when considering how students might progressively develop their interdisciplinary understanding over the course of their undergraduate degree.

The most benign level of interdisciplinarity described by Davies and Devlin is relational interdisciplinarity involving two or more disciplines providing perspectives on a common subject. In this way it shares similarities with multidisciplinarity (the difference being that with multidisciplinarity contributors need not discuss things with each other). Exchange interdisciplinary, another variant, involves the critical exchange of views while maintaining strong disciplinary integrity and boundaries (p.6).

Pluridisciplinarity involves a number of disciplines combining their expertise to address an area of common concern. Often the issue being addressed is too complex for a single discipline to deal with and requires the energies of specialists from different areas. In pluridisciplinary research there is typically a sharing of techniques, approaches and concepts. While the disciplines remain discrete, they cooperate with each other around a common area of interest when there is a particular need. While pluridisciplinarity often occurs naturally in academia, deliberate institutional and faculty strategies are likely to result in interdisciplinary exchanges that are intensified and more critical (Davies and Devlin, p.8). 
Davies and Devlin describe two more levels of interdisciplinarity: modification interdisciplinarity and transdisciplinarity. The former involves integration or even modification of the disciplinary contributions in the course of an inquiry. This often involves some kind of overall coordination from a higher hierarchical level. Importantly, "different participants need to take into account the contributions of their colleagues to make their own contribution." (p.8) Transdisciplinarity is described by Davies and Devlin as the most radical form of interdisciplinarity and involves the collapse of academic boundaries and the emergence of a new discipline.

The literature often refers to the first three variants of interdisciplinarity defined above when describing what the built environment discipline and profession are currently calling for to address significant and complex problems in the field (see for example Gann and Salter, 1999; Edwards et al., 2009; Chapman 2009).

The diagram in Figure 1 shows how the two key components of the CLE initiative map onto the continuum described by Davies and Devlin (2007). In developing the CLE initiative it was established that by the time students reach the senior years of their undergraduate degree they should be given opportunities to work with students from a range of built environment disciplines to provide disciplinary perspectives, engage in the critical exchange of views and address issues of common concern.

The question of what kind of activities might be suitable at the first year level was less straightforward. Students coming into first year do not have the disciplinary knowledge, skills and identity required to engage in pluridisciplinary activities. Introducing students to problems of an interdisciplinary nature at the beginning of first year however was seen to have its advantages. This sends a clear message to students that the ability to collaborate with peers and collectively solve problems is valued, and that these skills form the basis of effective interdisciplinary teamwork. Further, it places value on the synergies possible in collaboratively addressing issues of global concern over and above any particular skill set defined by disciplinary territories. Golding (2009) distinguishes between "interdisciplinarity without disciplinary depth" and "interdisciplinarity founded on disciplinary depth". He suggests that the former is an appropriate and useful model of interdisciplinarity for first and second year subjects, when students have not yet developed disciplinary expertise" (p.5).

A further strategy for incorporating interdisciplinarity into students' experience at the first year level was identified and involves modelling effective interdisciplinary exchanges for students. In the first week of their studies it is proposed that students have the opportunity to listen to panels of built environment professionals from a range of different disciplines debating complex, global issues as well as engage in workshops and projects that require them to explore some of the issues raised through a series of 'doing and making' activities. At the end of their first semester of studies, students would be required to reflect on the first week of the session and develop a more sophisticated understanding of the ways in which their 'home' discipline contributes to broader problems in the built environment. In this sense, the first year CLE can be seen as reflecting aspects of relational and exchange interdisciplinarity. While students will only be in the very early stages of establishing an identity with their 'home' discipline, they will have opportunities to collaboratively explore problems that are interdisciplinary in nature and to see interdisciplinary exchanges being effectively modelled.

BENIGN
Relational
Exchange
Pluridisciplinarity
Modification
Transdisciplinarity
EXTREME

Figure 1: Key components of the CLE initiative on the continuum described by Davies and Devlin (2007) 
While there are some clear differences between the activities considered appropriate for developing students' interdisciplinary knowledge and skills in first year as compared with senior years, they also share much in common. As suggested by Davis (1997), what an interdisciplinary experience is often really about is "recognizing contrasting perspectives; learning how to synthesize, think critically, and re-examine the world we take for granted; empowering students to tackle meaningful but complex issues; weaning students from dependence on experts without dismissing expertise; and teaching students to value disciplines as powerful sources of insight while becoming aware of the nature of their various limitations."

\section{THE CLE INITIATIVE}

The CLE initiative in the Faculty of Built Environment at UNSW proposes to develop students' interdisciplinary practice at two stages in their undergraduate degree program. These stages are described in detail below.

\section{Stage 1: First Year CLE}

A national study of the first year experience in Australian Universities has been conducted every five years since 1994. The study, run by the Centre for Studies in Higher Education at the University of Melbourne, highlights trends and issues pertinent to first year learning and teaching. It is clear from these studies that the first year CLE needed to be a highly engaging and relevant experience for students, and one that captures their interest and imagination while providing an opportunity for them to form social networks (James, Krausse and Jennings, 2010).

The interdisciplinary initiative in first year communicates a strong message to incoming students about the nature of their undergraduate education, the value of interdisciplinary collaboration to issues of global concern and the agency each student has with regard to these issues. Scheduled in the first week of the academic teaching session, the first year CLE provides a framework for learning prior to engagement with disciplinary knowledge and associated practice and research traditions. The intention is to 'leap frog' disciplinary boundaries in the harnessing of a 550-strong student cohort, where students participate in debates and contribute to exploring solutions around complex global human issues that extend beyond the scope of any single discipline.

\section{Aims and Learning Objectives}

The aims of the first year CLE are to:

- $\quad$ embed interdisciplinary learning into the curriculum from first year reinforcing it as a core faculty value (see BE Core Values, 2011);

- $\quad$ provide a first year experience that distinguishes BE at UNSW;

- $\quad$ create an exciting and engaging learning experience for first year students that gives them a sense of the broader BE arena and their place in it;

- $\quad$ introduce students to critical thinking and the contestability of knowledge;

- $\quad$ give importance to, and enable, learning for practice; and

- $\quad$ encourage the development of a social network for students early in their degree to support them as they progress through their studies.

Through participation in the common learning experience first year students will:

- $\quad$ engage with real world global issues;

- $\quad$ demonstrate generative, future-oriented thinking and making;

- $\quad$ engage productively in interdisciplinary learning and social networking; and

- demonstrate personal agency, initiative and responsibility for their learning. 
Themes

The process of 'thinking through making' is considered a commonality across the disciplines at BE and a way of uniting diverse research, technical and pedagogical agendas. The first year CLE intends to engage students in global 'game changers' that will impact practice for future generations e.g. energy, waste, urban densification, poverty, place, power, global communities, and social habitats. These issues will be investigated through different lenses across subsequent years according to opportunities presented such as research grants awarded, national conferences, competitions, and partnerships with community and industry. It is a critical condition of the experience that keynotes and debates involve expertise from both within and outside BE professions to offer alternate contributions to the theme.

Model

\begin{tabular}{|l|l|l|l|}
\hline \multicolumn{2}{|l|}{ AM } & $\begin{array}{l}\text { WELCOME AND GUEST } \\
\text { SPEAKERS }\end{array}$ & DEBATE \\
WORKSHOP 2 & $\begin{array}{l}\text { ALL DAY ALL-IN WORKSHOP 3 } \\
\text { (one site; 550 students) }\end{array}$ \\
$\begin{array}{l}\text { WM } \\
\text { Wo students } x 18 \text { groups (18 } \\
\text { tutors + 18 senior students with } \\
\text { participation from full-time staff) }\end{array}$ & $\begin{array}{l}\text { PREP SESSION for Workshop 3: } \\
\text { scenario setting (all 550 students + } \\
\text { senior students) }\end{array}$ & $\begin{array}{l}\text { DEBRIEF } \\
\text { (Making sense of the experience) }\end{array}$ \\
\hline
\end{tabular}

Figure 2: Structure of the First Year CLE: Week 1 activities

The proposed first year CLE model consists of a 3-day intensive experience in Week 1 of session (followed up with an assessment task and exhibition in Week 6) involving all first year undergraduate students across all programs. The 3-day intensive experience includes guest speakers, debates, a series of workshops, and a final exhibition of work completed. A range of guest speakers at the beginning of Day 1 will introduce students to the CLE topic to be explored, stimulate discussion and provide provocative and alternative perspectives on an issue. Guest speakers will be practitioners from various industries who are considered among the best in their field.

The debate on Day 2 will demonstrate diverse and conflicting perspectives on a central issue and show students that solving difficult global issues of real importance requires collaboration between disciplines within and outside the built environment. Modelling critical thinking-in-action through the debate is considered a very important part of the first year CLE. Debates will include both invited speakers and members of the BE and other UNSW Faculties.

The workshops that occur across the first two days are designed to draw on issues raised by guest speakers and in debates, and give students the opportunity to explore the central topic through thinking and making. Students will be working in mixed groups (i.e. with students from different programs) on workshop activities, giving them the opportunity to engage in group problem-solving and to form lasting social networks. The formation of social networks is considered vitally important for creating a positive first year experience and for overall student success.

The final workshop on Day 3 is an all-in workshop on the central theme with students responding to one core question in a making exercise. It is intended that that the final result will be a visual three-dimensional representation which reflects the three days of collaboration. A debrief which follows the final workshop is designed to bring students' learning from the three days together and help them make sense of the experience and how it connects with their further study. An exhibition of products from the workshops will conclude the three-day intensive with awards and recognition of the work achieved. 
The reflective task in Week 6 is designed to test students' understanding of both the content raised in Week 1 and to give students the opportunity to reflect on their learning experience. The added assessable component demonstrates to students that the BE values interdisciplinary learning and teaching as part of the curriculum. This task and the work from the week one intensive workshop sessions will be exhibited in the faculty.

\section{Stage 2: Senior years CLE}

The interdisciplinary learning initiative is extended into the senior years of undergraduate studies in a suite of interdisciplinary course offerings that capitalise on the diverse disciplinary capacities of the faculty and that engage students in meaningful disciplinary exchange. The courses offered at this level are considered truly interdisciplinary as students work in collaborative and cross disciplinary groups building on disciplinary expertise towards a solution to a common issue.

\section{Aims and Learning Objectives}

The third year interdisciplinary experience aims to:

- $\quad$ prepare students to work successfully in interdisciplinary teams in practice;

- $\quad$ empower students to tackle meaningful and complex issues through practice-based learning experiences;

- $\quad$ develop each student's sense of agency for change through disciplinary practice;

- $\quad$ develop opportunities for exchange and translation amongst built environment disciplines;

- $\quad$ expand the opportunities for the application of theory in practice; and

- develop a trajectory to PG research for those interested in further study.

The following outcomes draw on the unique advantages of the interdisciplinary learning setting. Courses in this interdisciplinary suite will determine more specific learning outcomes from this broad framework. Through participation in the common learning experience students will:

- $\quad$ understand the contribution of their particular discipline in its interdisciplinary context;

- develop skills in reflective practice to gain a better understanding of their respective professions by observing the reasoning and decision-making processes of peers;

- $\quad$ develop interdisciplinary teamwork skills;

- $\quad$ develop rigorous research and inquiry skills within the context of practice-based projects;

- $\quad$ generate effective solutions to real world problems through collaborative practice;

- $\quad$ think critically about professional identity and relationships; and

- develop an enhanced ability to integrate information and synthesise solutions through exposure to diverse perspectives.

The Model

The proposed third year common learning experience consists of a suite of interdisciplinary course offerings offered as 'interdisciplinary core courses' in the senior years of the undergraduate program. The suite of courses is described under four broad clusters: BE Design Competition, Engagement, BE Inquiry and Urban Projects. These clusters develop existing industry, community and civic partnerships, offer national and global exposure to studio-based expertise particular to BE disciplines and build research capacity within the undergraduate cohort.

The courses would be available to students who have completed 96 units of credit (UOC) or more of a 144 UOC, 4-year undergraduate degree (typically at the end of year 2 through to graduation). Students choose two courses from the suite of offerings to total a minimum of $12 \mathrm{UOC}$ in interdisciplinary studies. Enrolment in courses will be 'socially engineered' to ensure students from a minimum of three disciplines are enrolled in each course. All courses will focus on relevant and real world activities and experience, draw on sponsorship and partnerships where possible and be visible through a digital presence, exhibition or publication. Assessment will focus on work in 
collaboration (integrative work) along with students' reflection of their disciplinary contribution to the interdisciplinary context (supported by Boix \& Duraising, 2007; Golding, 2009).

The CLE models described in this paper lay out a framework for embedding interdisciplinary experiences in the Faculty's undergraduate curriculum. Business cases for both stages of the CLE initiative were developed in consultation with working parties of academics from each discipline field. These cases were presented to various committees and forums across the faculty for feedback and endorsement. Along with a pedagogical rationale and the development of the proposed model with resource and governance implications outlined, the business cases provided recommendations for sponsorship from the built environment executive team. These recommendations outlined the need to prioritise this initiative in long-term faculty strategic and budget forecasting involving: ongoing evaluation and development of the proposed models; the provision of support and opportunities for staff engagement; marketing and communication strategies; and changes to governance structures to facilitate systematic implementation across the faculty. The initiative was supported by BEE and approved for implementation in 2013. The next steps involve detailed articulation and coordination of the workshops that make up the first year CLE, further development of courses and projects for the CLE in the senior undergraduate years, implementation of governance changes, and the development of evaluation tools to examine the effectiveness of the initiative.

\section{Factors contributing to the development and sustainability of the initiative}

The significance of the CLE is in the faculty commitment to a sustained and enterprise-wide redirection of learning and teaching priorities. The new concept of education being proposed at BE argues for a blurring of current disciplinary boundaries and a reconceptualization of learning based on a vision that is future-driven, globally focused, and includes authentic engagement in partnerships with communities and industry.

The CLE represents one project in a series of interdisciplinary curriculum initiatives that signify a faculty repositioning in teaching and research. Other initiatives include:

- Instituting new, and revising existing, interdisciplinary graduate research and coursework programs

- $\quad$ Developing an interdisciplinary research methods course for all new graduate degree programs

- $\quad$ Promoting pathways to higher degree research for design-oriented programs including investigating professional doctorate opportunities

To support change on this scale it is necessary to identify the conditions that will lead to the effective development and sustainability of the initiative. Dubrow and Harris (2006) make a series of recommendations for supporting and sustaining interdisciplinary initiatives at the University of Washington. The following are highly relevant to the context under discussion:

- $\quad$ Encourage upper level administrative leadership to better seed, support, and sustain interdisciplinary initiatives

- $\quad$ Clarify options for administrative homes and structures for interdisciplinary initiatives

- $\quad$ Re-examine academic policies and practice regarding Faculty appointments and promotion to facilitate and reward interdisciplinary activities

- $\quad$ Develop policies and practices that promote the intellectual mobility of faculty over the course of their careers, such as allowing them to commit part of their appointment or move their primary appointment to other units, including interdisciplinary initiatives

- Identify and disseminate best practices related to the student experience in interdisciplinary programs

- Identify appropriate additional investments in interdisciplinary program budgets

- $\quad$ Conduct additional research to better understand interdisciplinary Faculty and student experiences

- $\quad$ Affirm the shared responsibility of the Faculty to prepare future faculty and professionals to cross disciplinary boundaries in pursuit of knowledge and solutions to pressing societal problems (p.5)

All of these strategies have the potential to improve the environment for interdisciplinary initiatives and contribute to their longevity. In addition to these strategies it will be important to continue to make genuine links 
between the various interdisciplinary initiatives in the Faculty, as evidence suggests this is also a key factor in sustaining interdisciplinary programs and activities (Holley, 2009).

The experience of coordinating the development of the CLE framework supports the notion that facultywide research and curriculum redirection of this kind requires two critical elements for success: ownership by academic staff and leadership by faculty management to facilitate meaningful and sustainable change. Staff ownership of the proposal and its development with regard to pedagogy, delivery, assessment and measures of success were critical to meaningful engagement with the initiative. The working group facilitated a collaborative process amongst staff in the development of the CLE models. This engagement with academic staff at various intervals and in different forums was critical. Prior to establishing staff working groups a discussion paper was sponsored by Faculty management. The paper summarised current scholarship and best practice case studies and posed key questions to assist faculty discussion and the development of the initiative (see Wilson, 2011). Throughout the development, working groups expanded and reshaped the framework as necessary, held broad informal consultations and workshops and presented models for feedback across various committees within the faculty. This facilitated a sense of ownership and accountability for the proposal driven by the pedagogical values of academic staff. The ownership of the CLE by the staff group 'levered' this initiative from an item driven by the BE executive in the faculty strategic direction process to a marker of real curriculum change driven by the staff responsible for facilitating the student experience.

In addition to faculty staff engagement, the commitment of faculty leadership to the development of interdisciplinary initiatives, including resources and incentives for development, is critical. Leadership is required to sponsor the change in governance structures and values represented in the redirection of resources. As the volume of interdisciplinary activity increases in the faculty, and with the development of more engaged external partnerships, the need for centralised, faculty-wide coordination and oversight of these opportunities and courses also increases. A coordinated approach in this area will ensure a more sustainable integration of these initiatives within the Faculty. It will also ensure that the beneficial experience of these projects, courses and programs is captured, enhanced and maximised. Having leadership and resource support will increase the likelihood of this philosophical and pedagogical approach becoming embedded in the Faculty program with resultant benefits for learning, teaching and research.

In the CLE proposal two new leadership positions were recommended to lead the implementation of the initiative to ensure recognition and resourcing for the long term. It has been proposed that two Interdisciplinary Academic positions be established (full-time senior lecturer positions) to ensure that opportunities for collaboration are effectively and consistently integrated across all faculty programs. This strategy will also reduce the occurrences of interdisciplinary efforts being concentrated in particular areas or disciplines. The primary responsibilities of the positions would be to:

- $\quad$ Coordinate and teach into interdisciplinary experiences in first year and senior years

- $\quad$ Coordinate the development of civic and industrial partnerships

- $\quad$ Lead a BE student e-portfolio assessment initiative

- $\quad$ Coordinate evaluation and improvement of the initiative in the long term

A number of other components were identified by academic staff as having the potential to improve and sustain the initiative in the longer term, and represent staff willingness to extend the impact of the CLE. These include:

- $\quad$ Establishing the CLE as an action research project. Incorporating research, reflection, assessment and redesign into the CLE communicates a strong message of quality assurance, research, collaboration and community engagement to the undergraduate student community.

- Introducing an e-folio for all students. The e-folio would be used to record student work, to encourage self-reflection and critical thinking, to assist students in demonstrating and understanding their own competencies, to help staff track student progress, and allow students to present a comprehensive overview of academic work and supporting evidence (artefacts) to a potential employer. Students would begin to use the portfolio as part of the first year CLE, and continue to use it throughout their degree (i.e. through to their capstone year). 
- $\quad$ Sponsorship. The Working Group has acknowledged that seeking industry partnerships for interdisciplinary courses is an important consideration in terms of fiscal viability and the student experience.

- $\quad$ Research opportunities. The CLE provides a range of research opportunities for the faculty. For example, Faculty research clusters could be involved in developing courses for delivery with research components and outputs. Alternatively, research grant successes of the faculty could offer courses within the suite.

- $\quad$ Marketing opportunities. This initiative must be accompanied with a marketing and communication plan to showcase these courses as representative of the faculty's redirection and distinction amongst its competitors.

A faculty commitment to the assessment and quality assurance of this initiative will allow such innovations to be tested in the development of the CLE in the long term.

As a component of the strategic repositioning of the faculty, the CLE proposal has the potential to change the landscape of undergraduate studies in the faculty. By locating interdisciplinary learning as central to the development of graduate capabilities, disciplines are engaged, challenged and redefined through the collaborative process. Students are able to draw on a range of perspectives and methods for creative problem solving across and beyond discipline territories. Traditional conceptions of professions are investigated and new concepts of enquiry and collaboration examined. For professional degree programs in particular, the CLE repositions the student and staff experience as critically engaged with the collaborative and contemporary work practices of industry. It also provides the academic community with an opportunity to examine its own traditions of learning and teaching and develop new concepts of collaboration and leadership.

\section{ACKNOWLEDGEMENTS}

With thanks to the members of the CLE Working Group: Nancy Marshall, Steve Ward, Russell Rodrigo, Kate Bishop, Linda Corkery, Rina Bernabei, Catherine Bridge, Ann Quinlan; and the members of academic staff that participated in the wider consultation process: Russell Lowe, Chris Walsh, Jeremy Harkins, Peter Graham, Steve King, Stephen Peter, Peter Murray, Paola Favaro, Tom Loveday, Christine Steinmetz, Mariano Ramirez, Riza Sunindijo, Jinu Kim, Oya Demirbilek, Sid Newton, John Woollett, Paola Favaro, Catherine Evans, Larry Hulbert, Jan Orrell, Marayam Gusheh, Hoon Han and Cynthia Wang.

\section{AUTHOR INFORMATION}

Lisa Zamberlan is a Senior Lecturer, Academic Fellow in Learning and Teaching and Design Studio Leader at the Faculty of Built Environment, University of New South Wales. Affiliation: Faculty of Built Environment, University of New South Wales, Australia 2052. E-mail: lisa.zamberlan@unsw.edu.au (Corresponding author)

Stephanie Wilson has a background in music teaching and research, attaining a $\mathrm{PhD}$ with the School of Music at the University of New South Wales (UNSW). After completing a Graduate Certificate in University Learning and Teaching she worked for the UNSW Learning and Teaching Unit to coordinate projects, facilitate workshops and develop resources to support academics with their teaching practice. In 2009 Stephanie was Project Manager of a national ALTC project investigating curriculum development in studio teaching. Stephanie is currently part of an education team working on a range of learning and teaching initiatives in the Faculty of the Built Environment at UNSW. Affiliation: Faculty of Built Environment, University of New South Wales, Australia 2052.

\section{REFERENCES}

1. BE Core Values (2011). Office of the Associate Dean Education, Faculty of Built Environment, University of New South Wales.

2. BE Program Directions 2011-2015 (2011). Office of the Associate Dean Education, Faculty of Built Environment, University of New South Wales.

3. BE Strategic Plan (2009). Faculty of Built Environment, University of New South Wales.

4. Billett, S. (2009). Realising the educational worth of integrating work experiences in higher education, Studies in Higher Education, 34(7), 827-843. 
5. Boix, M. \& Duraising, E. (2007). Targeted assessment of students' interdisciplinary work: An empirically grounded framework. Journal of Higher Education, 78(2), 218-237.

6. Built Environment Retreat (December 2010). Workshop notes compiled by Linda Corkery and Peter Graham. Faculty of Built Environment, University of New South Wales.

7. Chapman, D.W. (2009). Knowing our places? Contexts and edges in integrating disciplines in Built Environment education. Journal for Education in the Built Environment, 4(2), 9-28.

8. Corkery, L. (2007). Learning and teaching across disciplinary cultures in built environment design education. Presented at Seminar on Design Education 2007. South East University, Nanjing, China, January 2007.

9. Davies, M. \& Devlin, M. (2007). Interdisciplinary higher education: Implications for teaching and learning. Centre for the Study of Higher Education, University of Melbourne.

10. Davis, J.R. (1997). Interdisciplinary Courses and Team Teaching. Phoenix: American Council on Education/ Oryx Press Series on Higher Education.

11. Dubrow, G. \& Harris, J. (January, 17, 2006). Seeding, Supporting, and Sustaining Interdisciplinary Initiatives at the University of Washington: Findings, Recommendations, and Strategies. Draft for public comment. The Graduate School, University of Washington.

12. Edwards, M., Campkin, B. \& Arbaci, S. (2009). Exploring roles and relationships in the production of the built environment. CEBE Transactions, 6(1), 38-61.

13. Gammal, R. (2009). Laying the foundation for a new Great Problems Seminar with an environmental focus. Project Report. Worcester Polytechnic Institute.

14. Gann, D. \& Salter, A. (1999). Interdisciplinary Skills for Built Environment Professionals. London: The Ove Arup Foundation.

15. Golding, C. (2009). Integrating the disciplines: Successful interdisciplinary subjects. Centre for the Study of Higher Education. University of Melbourne.

16. Holley, K.A. (2009). Interdisciplinary strategies as transformative change in higher education. Innovations in Higher Education, 34, 331-344.

17. James, R., Krause, K., \& Jennings, C. (2010). The First Year Experience in Australian Universities: Findings from 1994-2009. Centre for the Study of Higher Education, The University of Melbourne.

18. Jones, P.C. \& Merrit, J.Q. (1999). Critical thinking and interdisciplinarity in Environmental Higher Education: the case for epistemological and values awareness. Journal of Geography in Higher Education, 23(3), 349-347.

19. Savage, S., Davis, R., \& Miller, E. (2010) Professional Education in Built Environment and Design. A report prepared for the Australian Learning and Teaching Council (ALTC).

20. Stone, T., Bollard, K., \& Harbor, J. (2009). Launching interdisciplinary programs as college signature areas. Innovations in Higher Education, 34, 321-329.

21. The Boyer Commission on Educating Undergraduates in the Research University (1998). "Remove Barriers to Interdisciplinary Education" in Reinventing Undergraduate Education: A Blueprint for America's Research Universities, State University of New York, New York.

22. University of New South Wales (April, 2011). B2B Blueprint to Beyond: UNSW Strategic Intent. Office of the President and Vice-Chancellor, University of New South Wales.

23. Wilson, S. (2011). Common Learning Experiences in the Built Environment: A Discussion Paper. Unpublished report. Office of the Associate Dean Education, Faculty of Built Environment, University of New South Wales. 